\title{
Variables associated with the life satisfaction of elderly caregivers of chronically ill and dependent elderly relatives
}

Abstract

Objective: to compare the life satisfaction of family caregivers, taking into account their gender, age, time since starting care, health, religion, perceived burden and quality of life, and the level of physical and cognitive dependence of the elderly person receiving care, and to investigate the associations between these variables and low life satisfaction. Methods: a total of 148 caregivers in Indaiatuba and Campinas, in the state of São Paulo, Brazil, selected using the convenience method, were interviewed at home, in private medical clinics and outpatient units, using questionnaires about the sociodemographic characteristics, health conditions, time since starting care, scales of life satisfaction, religiosity, perceived burden and quality of life of the caregiver, and the physical and mental health of the elderly person receiving care. Descriptive, Multivariate and Univariate Logistic Regression analysis were used. Results: caregivers who exhibited low life satisfaction included more frail individuals, with three or more chronic diseases and depression, greater perceived burden and lower self-fulfillment and pleasure, and control and autonomy, scores, which are factors of the Perceived Quality of Life Scale. Elderly caregivers who scored low in self-fulfillment factor and pleasure $(\mathrm{OR}=101.29$; $\mathrm{CI}=28.68-357.73)$ and who scored high in perceived burden ( $\mathrm{OR}=5.89, \mathrm{CI}=2.13$ to 16.24$)$ had a greater chance of having low life satisfaction scores. Conclusions: The assessment of caregivers of their satisfaction with life is more influenced by subjective than objective variables, and low satisfaction seems to be strongly associated with poor quality of life, high burden, and caregiver frailty.

\footnotetext{
Universidade de Campinas, Faculdade de Ciências Médicas, Programa de Pós Graduação em Gerontologia. Campinas, SP, Brasil.

2 Universidade de São Paulo, Escola de Artes, Ciências e Humanidades, Curso de Graduação em Gerontologia. São Paulo, SP, Brasil.

Research funding: Coordination for the Improvement of Higher Education Personnel. Process $\mathrm{N}^{\mathrm{o}}$ : 01P1741/2016

Rebeca de Barros Caldeira'

Anita Liberalesso Neri ${ }^{1}$

Samila Sathler Tavares Batistoni²

Meire Cachioni²

Keywords: Personal Satisfaction. Family Caregivers. Aged. Quality of Life. 


\section{INTRODUCTION}

Life satisfaction, one of the cognitive indicators of subjective well-being linked to negative and positive affects, is a widely studied concept in gerontological literature ${ }^{1}$. According to Campbell, life satisfaction is defined as the distance between the individual's perception of their own reality and their aspirations and desires ${ }^{2}$.

Research aimed at specific populations, such as family caregivers of dependent elderly people, has identified paradoxical results. There are indications that being a caregiver negatively affects an individual's satisfaction with life, as they feel unprepared and physically and psychologically exhausted, as well as unsupported in the performance of their role ${ }^{3,4}$. However, some authors note that caregivers are as satisfied as non-caregivers, which can be explained by their ability to adapt to difficulties and create strategies to overcome problems and challenges, as well as the perception that they benefit by caring for others, in terms of learning and self-confidence ${ }^{5,6}$.

Research also shows that gender and age may influence the perception of satisfaction of caregivers. According to Hajek and König, being female increases the chances of low life satisfaction, which can be explained by the fact that women are more susceptible to chronic diseases and disabilities, as well as having to adopt other roles in their households ${ }^{8}$. The age of caregivers may also influence their perception of life satisfaction, as verified by a study conducted by Anderson et al. ${ }^{9}$, in which caregivers aged 18-64 years were 7.6 times more likely to feel dissatisfied than caregivers aged more than 64 years. However, Tomomitsu et al. ${ }^{10}$ when verifying the levels of life satisfaction of caregivers of elderly persons, did not find significant differences between groups of caregivers aged $65-69,70-74,75-79$ and 80 years and over, which may be explained by the fact that younger caregivers suffer less from burden and physical overload than older caregivers, yet have more responsibilities and demands in addition to providing care, which may make the caregiver groups equal.

The health conditions of caregivers and the degree of physical and cognitive dependence of the elderly care recipient also influence the satisfaction of caregivers with their lives. Individuals who care for elderly people who are dependent for physical reasons tend to be more satisfied than those who care for elderly persons who are dependent because of cognitive impairments, as this second group often must deal with the mood and behavioral changes of the elderly, aspects that negatively affect well-being ${ }^{11}$. In addition, caregivers who report having poor health or diseases are significantly more dissatisfied than those who do not have any illness, as the association between poor health and the burden of care affect the perception of satisfaction of the caregiver ${ }^{5,12}$.

Life satisfaction is significantly associated with depressive symptoms, as shown by a study conducted by Moreno et al. ${ }^{13}$. Caregivers with the greatest risk of developing depression are those who score lower for life satisfaction. In addition to depression, burden, a concept that encompasses physical, emotional, financial and social aspects ${ }^{14}$, directly affects the perception of caregivers of their life satisfaction and well-being. High levels of life satisfaction seem to be a protective factor against burden and depressive symptoms ${ }^{15,16}$.

The quality of life of caregivers has been extensively explored in literature. Quality of life is directly related to high levels of life satisfaction among this group, since these two factors influence each other and evolve in a mutual fashion ${ }^{17,18}$.

Considering the significant increase in the number of elderly persons who have some kind of dependency and who require the care of another elderly person, the aim of the present study was to produce useful knowledge to better understand this model in the context of Brazil, as well as to contribute to theoretical support for the planning and evaluation of instrumental and social skills training programs; the development of knowledge about care strategies, and the understanding and improvement of cognitive-emotional self-regulation plans aimed at family caregivers of chronically ill and dependent elderly persons. Thus, the present study aimed to analyze the life satisfaction of elderly caregivers of elderly persons, considering the variables gender and age, time since starting care, health conditions, the burden and perceived quality of life of the caregiver, as well as the level of physical and cognitive dependence of the elderly person receiving care, and to investigate associations between these variables and low life satisfaction. 


\section{METHOD}

A cross-sectional study was conducted based on a convenience sample of 148 elderly caregivers living in the cities of Jundiaí, Vinhedo, Indaiatuba and Campinas, Brazil, who cared for equally elderly relatives. The participants were suggested by public and private health care services, home care, doctors, professionals of the Family Health Program and Basic Health Units and the Geriatrics Outpatient Clinic of a university hospital.

The sample size of 148 caregivers required for the correlation analysis between the scores of the scales used was calculated based on the Pearson model, with Fisher's transformation, considering a significance level of $1 \%$, a test power of $90 \%$, a zero correlation of 0.10 , and a minimum correlation of 0.40 .

Caregivers had to be 60 years of age or older and have been caring for an elderly relative for at least six months to be eligible for the survey. Caregivers aged 60 to 69 years who scored 22 points or less and caregivers aged 70 and over who scored 19 points or less on the cognitive test Cognitive Abilities Screening Instrument - Short Form were excluded ${ }^{19}$.

The interviews were conducted from October 2014 to October 2015. Each interview lasted about one hour and was conducted in the homes of the individuals, private doctors' surgeries and the Geriatrics Outpatient Clinic of a university hospital. Seven trained interviewers, originating from a master's and doctorate program in Gerontology, carried out the interviews in locations and schedules previously agreed with the participants.

The main study entitled "Psychological wellbeing of elderly caregivers of elderly persons in a family context" included several blocks of variables, as listed below:

a) Life satisfaction: evaluated with the Global Life Satisfaction Scale ${ }^{20}$, with five items in Likert format, each with seven points, which, in the present study, were adjusted by the authors and reduced to five. For analysis, these were grouped into low satisfaction (17 points or less), moderate satisfaction (between 18 and 21), high satisfaction (22 and more), scores validated for the Brazilian population. b) Sociodemographic characteristics: questions about gender, date of birth and age in years.

c) Time since starting care (in months): single question about how long the caregiver has performed the function.

d) Health conditions: self-reported measures of chronic diseases, frailty and depressive symptoms. Diseases were measured through nine items evaluating whether a doctor told the elderly person that they had one or more chronic illnesses. The numbers of diseases were grouped into bands (none, 1 or 2 and 3 or more). The frailty measure included five self-reported questions, with caregivers who scored zero in all the criteria classified as either robust or non-frail; those who scored in one or two criteria classified as pre-frail, and those who scored in three or more criteria classified as frail ${ }^{21}$. The depressive symptoms were analyzed by the Geriatric Depression Scale, 15 item version, using a cut-off point greater than or equal to six points, as adopted in Brazil ${ }^{22}$.

e) Level of impairment in Activities of Daily Living: the degree of dependency of the elderly caregiver for the performance of Instrumental Activities of Daily Living (IADL) and Basic Activities of Daily Living (BADL) was evaluated respectively by the Lawton and Brody Scale. The response options are totally independent, need partial help or need total help. The BADL and IADL that the elderly persons were unable to perform without total or partial help were added together and, from the total value, the elderly were considered capable (zero to six impaired activities), moderately incapable (seven to twelve impaired activities) and incapable (13 and more impaired activities).

f) Cognitive status: we used the Clinical Dementia Rating (CDR ${ }^{23}$ instrument, which scores the degree of impairment of memory, orientation, judgment and problem solving, community relations, home and hobbies, and personal care from zero to three. The classification adopted for a low level of impairment was from zero to 0.5 points, for a moderate degree of impairment, from 1 to 2 points and, for a high degree of impairment, 3 points. 
g) Religious involvement: Measured through the Duke University Religion Index (DUREL) ${ }^{24}$. With five items, the stipulated ranges were: $<19$ $=$ low religious involvement; 20 to $22=$ moderate religious involvement and 23 points and more $=$ high religious involvement.

h) Perceived burden: Evaluated through the Zarit and collaborators Burden Scale, which consists of 22 items that reflect aspects of the caregiver's discomfort with their health, personal and social life, financial situation, emotional well-being and interpersonal relationships ${ }^{25}$. In this study, the scale was divided into three factors: role-related stress, intrapsychic tensions and competence and expectations related to care. Cronbach's $\alpha$ was 0.87 , indicating good internal consistency of the scale items as a whole. The distribution of the total scores of caregivers was divided into terciles: 19 points or less corresponded to low burden, 20 to 27 moderate burden and 28 or higher to high burden.

i) Quality of life: measured through the CASP-19 $9^{26}$ scale, which has 19 items in Likert format and a score ranging from zero to 57 . The distribution was divided into terciles: 40 points or less indicated a poor quality of life, 41 to 47 points moderate quality of life and 48 points and more, high quality of life. The acronym CASP means control, autonomy, self-realization and pleasure, which are the factors of the scale. In this study two factors were considered: self-realization and pleasure (factor 1) and control and autonomy (factor 2): generated by confirmatory factor analysis.

The levels of life satisfaction of caregivers (low $<17$, moderate $=18-21$ and high $>22$ ) were compared based on the independent variables. Because of the non-normal nature of the distributions, chi-square and Fisher's exact tests were used to compare the categorical variables between the three groups. For the comparisons with numerical variables or scores between the three Life Satisfaction groups, the Kruskal-Wallis test was used, due to the absence of normal distribution of the variables, followed by Dunn's multiple comparisons test.

To study the variables associated with lower life satisfaction and the independent variables, univariate and multivariate logistic regression analyzes were used, with stepwise variable selection criteria. The level of significance adopted for the statistical tests was $5 \%$.

The project was approved by the Ethics Research Committee of the Universidade Estadual de Campinas (Campinas State University) (CAAE $\mathrm{n}^{\mathrm{o}}$ 35868514.8.0000.5404) (Annex 1), which also approved the Free and Informed Consent Form (FICF), which was read and signed by all caregivers after they were informed about the objectives, content and duration of the interview, the conditions of participation and the rights of the participants.

\section{RESULTS}

There was a tendency of greater burden among those who with low life satisfaction. More caregivers with high scores for factors 1 (role-related tensions) and 2 (intrapsychic tensions) had intermediate levels of satisfaction, and more elderly patients with high satisfaction had a low score in terms of perceived burden. A lower total score on the quality of life scale and factors 1 (self-realization and pleasure) and 2 (control and autonomy) were observed in caregivers with a low life satisfaction score. However, 96.4\% of the elderly who had a high life satisfaction score also obtained a high score in perceived quality of life, with the same results obtained for the self-realization and pleasure and control and autonomy factors. The Kruskal-Wallis test and the Multivariate Regression Analysis indicated that caregivers with low life satisfaction had significantly higher means for frailty, chronic diseases, depression and burden, while lower mean life satisfaction scores were observed among caregivers with low satisfaction than among those with intermediate and high satisfaction (Table 1). 

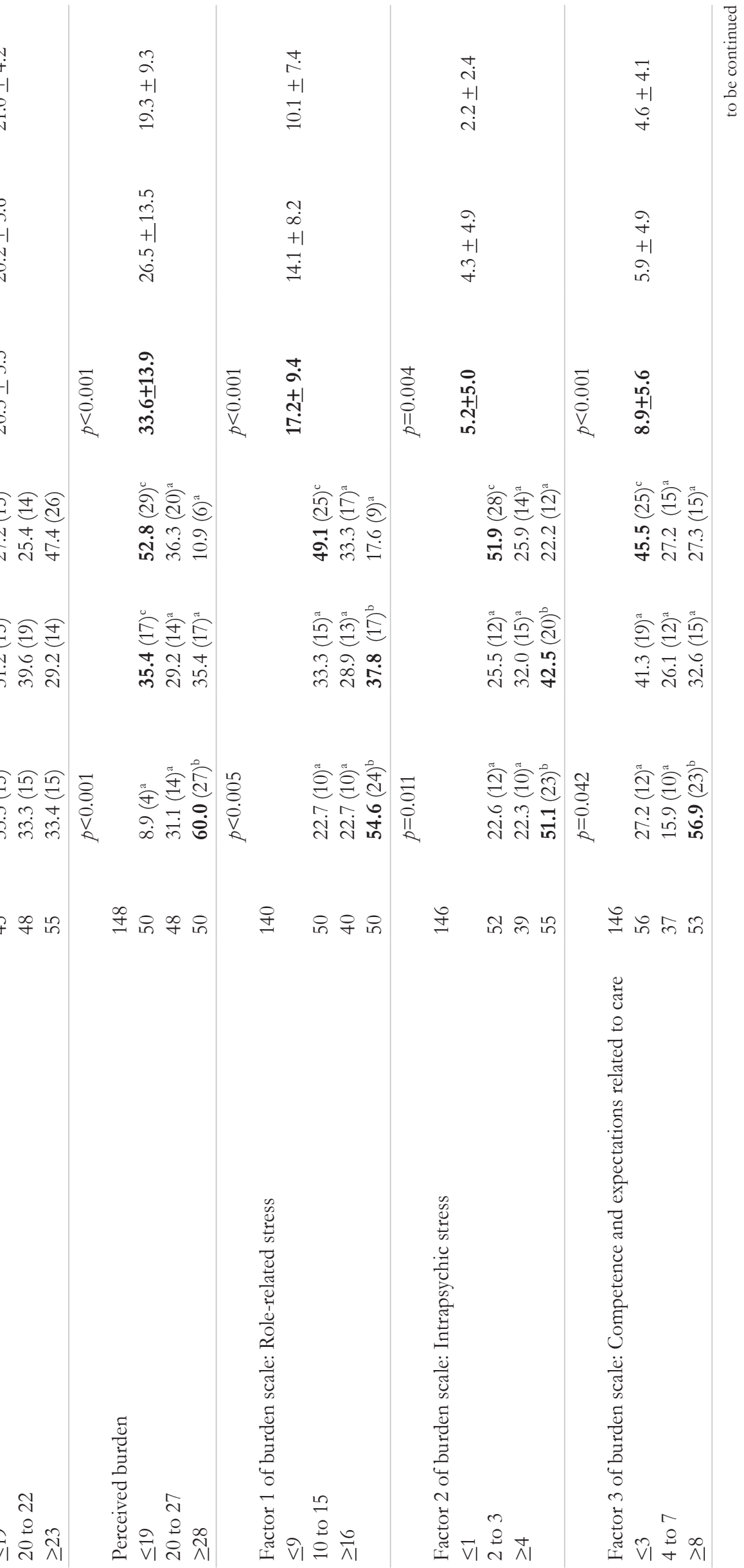


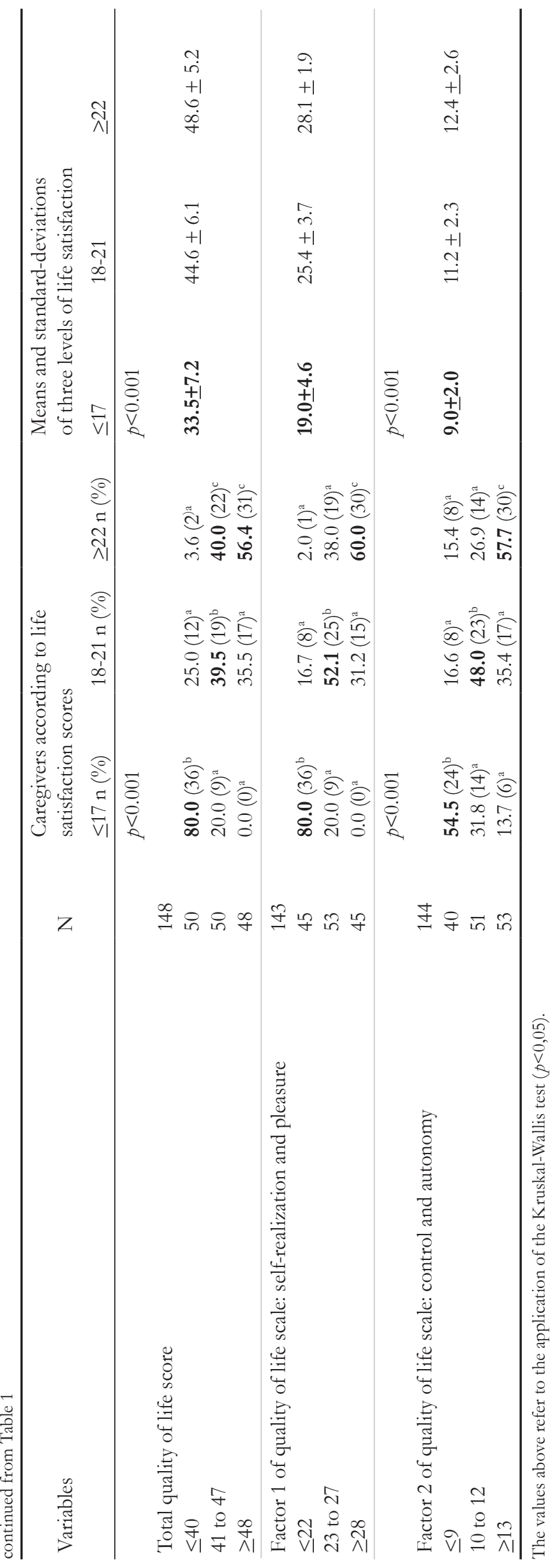




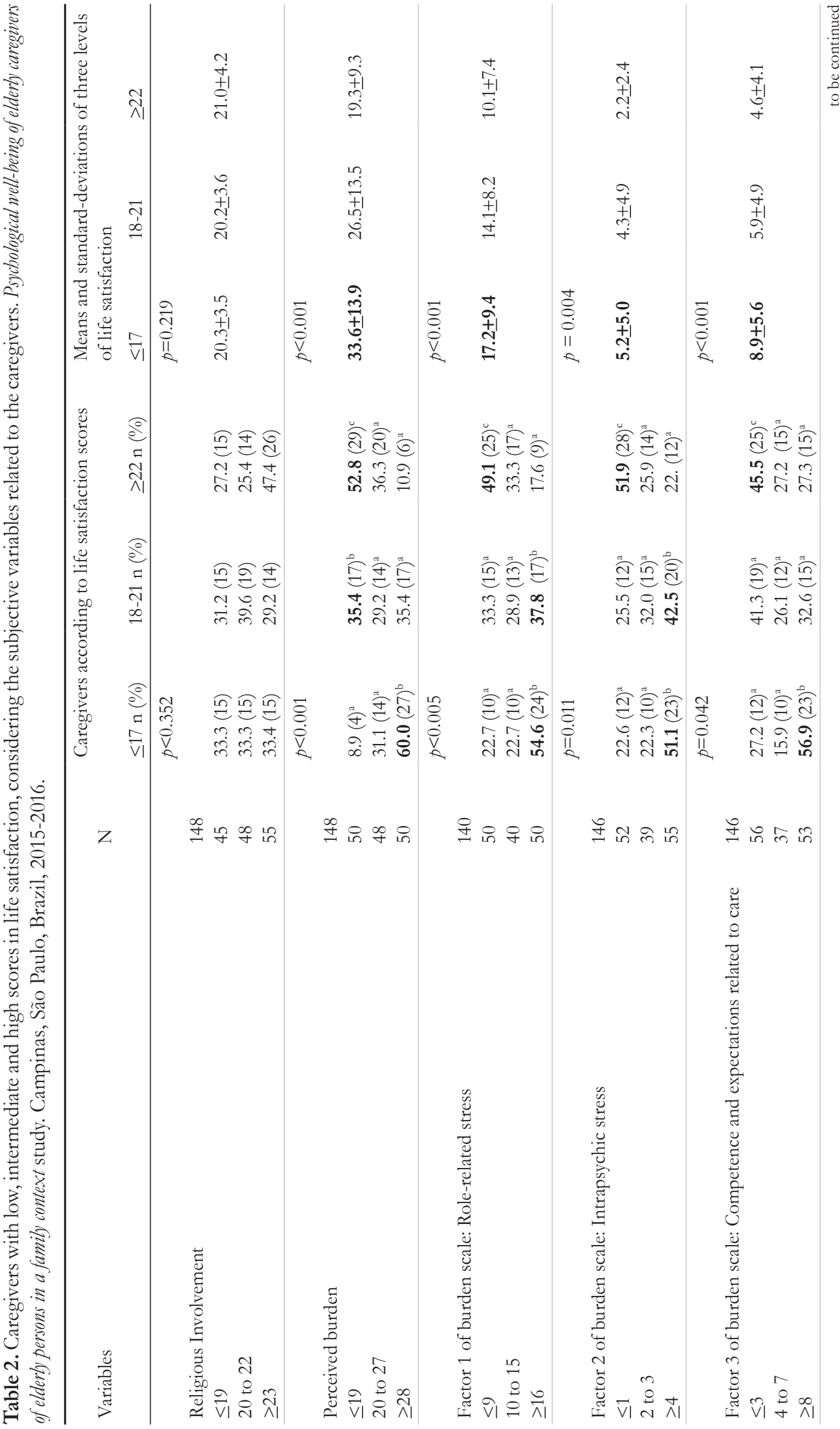




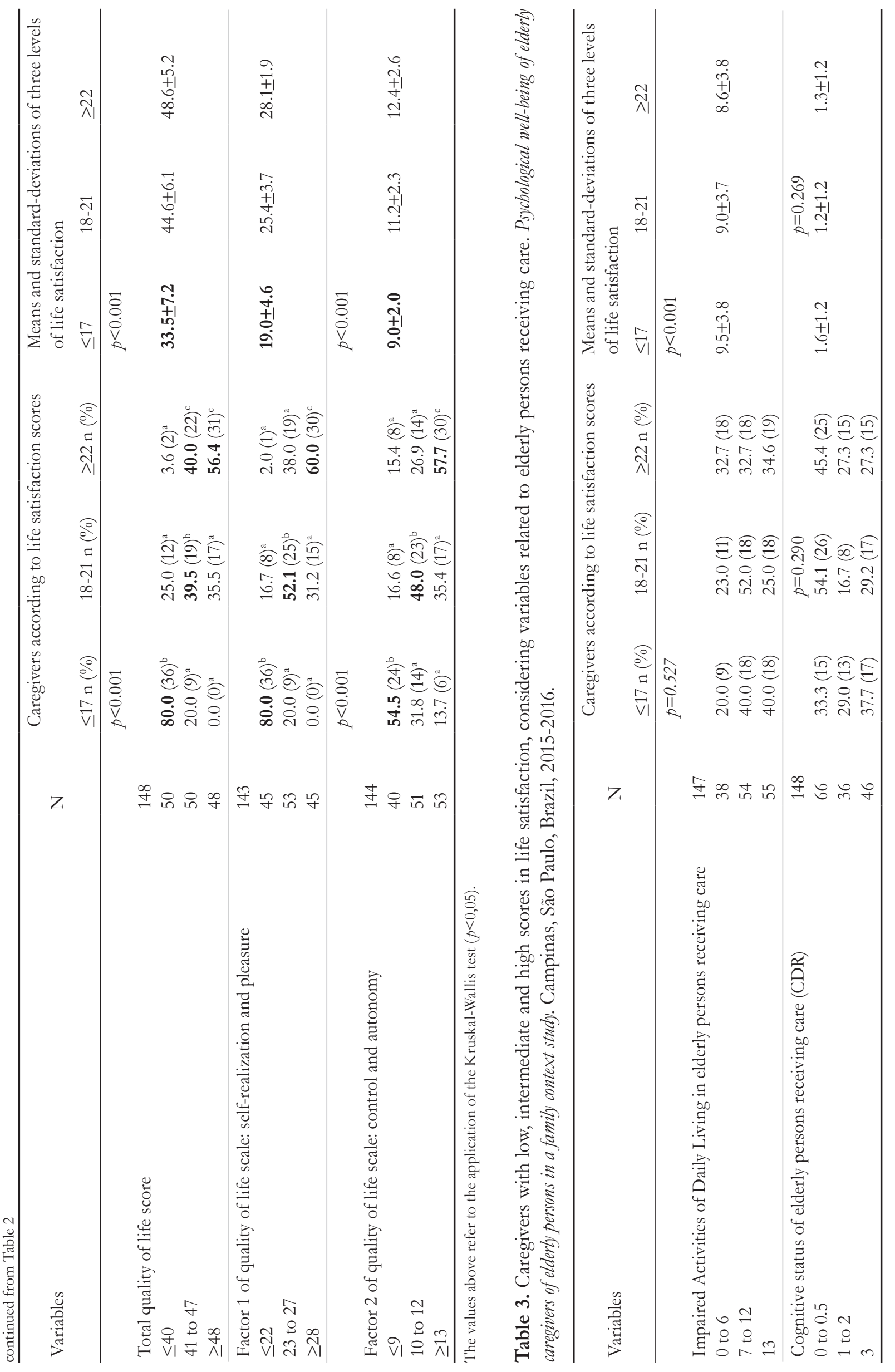


A greater frequency of frail than pre-frail and non-frail caregivers was observed among those with low satisfaction scores, and higher frequencies of robust and pre-frail caregivers among those who achieved high and intermediate satisfaction scores. More caregivers with low satisfaction scores reported having three or more chronic diseases than elderly persons who reported having one, two, or none. There were proportionately more elder persons with one, two or no illnesses among those with high life satisfaction scores, and older patients with one or two chronic diseases than three or more, or none, among those with intermediate satisfaction scores. There were more elderly caregivers who scored for depression among those who had low life satisfaction, and more caregivers who did not score for depression among those who had high and intermediate levels of life satisfaction (Table 4).

Univariate logistic regression analysis also revealed that the variable with the most robust association with low life satisfaction was self-realization and pleasure, factor 1 of the quality of life scale. Caregivers who scored below the first tercile in this factor were 100 times more likely to score for low satisfaction than those who scored above the third tercile. Those who scored below the second tercile in this variable had a 4.17 times greater chance of a low satisfaction score.

Other variables that presented a statistically significant association with low life satisfaction were: total perceived burden scale score, control and autonomy (factor 2 of the quality of life scale), intrapsychic stresses (factor 2 of the burden scale), depression, role-related stress (factor 1 of the burden scale) and competence and expectations related to care (factor 3 of the burden scale), frailty and total score in the quality of life scale.

Caregivers with intermediate levels of life satisfaction, control and autonomy and perceived burden were, respectively, 2, 3 and 2.5 times more likely to score for low satisfaction than the caregivers taken as a reference (Table 4).

Table 4. Results of univariate logistic regression analysis for low life satisfaction ( $\mathrm{n}=148)$. Psychological well-being of elderly caregivers of elderly persons in a family context study. Campinas, São Paulo, Brazil, 2015-2016.

\begin{tabular}{|c|c|c|c|}
\hline Variables and Categories & $p$-value & O.R.* & CI $95 \%$ O.R.* \\
\hline \multicolumn{4}{|c|}{ Time since start of care (years) } \\
\hline$\geq 5$ & --- & 1.00 & --- \\
\hline $2-4,9$ & 0.441 & 1.32 & $0.65-2.71$ \\
\hline$<2$ & 0.291 & 1.51 & $0.70-3.22$ \\
\hline \multicolumn{4}{|l|}{ Gender of caregivers } \\
\hline Male & --- & 1.00 & --- \\
\hline Female & 0.266 & 1.50 & $0.74-3.05$ \\
\hline \multicolumn{4}{|l|}{ Age of caregivers } \\
\hline $60-64$ & --- & 1.00 & --- \\
\hline $65-74$ & 0.641 & 0.85 & $0.42-1.71$ \\
\hline$\geq 75$ & 0.463 & 0.74 & $0.33-1.66$ \\
\hline \multicolumn{4}{|l|}{ Level of frailty of caregivers } \\
\hline Robust & --- & 1.00 & --- \\
\hline Pre-frail & 0.553 & 0.78 & $0.34-1.77$ \\
\hline Frail & 0.018 & 2.85 & $1.20-6.77$ \\
\hline \multicolumn{4}{|c|}{ Number of diseases of caregivers } \\
\hline 0 & --- & 1.00 & --- \\
\hline $1-2$ & 0.966 & 1.02 & $0.46-2.23$ \\
\hline$\geq 3$ & 0.084 & 2.10 & $0.91-4.86$ \\
\hline \multicolumn{4}{|c|}{ Score above depression scale cut-off point (caregiver) } \\
\hline No & --- & 1.00 & --- \\
\hline Yes & $<0.001$ & 7.69 & $3.46-17.06$ \\
\hline
\end{tabular}


continued from Table 4

Score of caregivers in religious involvement scale

(in terciles)

$\geq 23$

20-22

$\leq 19$

0.155

1.68

Total score of caregivers in perceived quality

0.201

1.61

$-3.45$

of life scale (in terciles)

$\geq 48$

$---$

1.00

$---$

$41-47$

0.010

2.86

$1.29-6.35$

$\leq 40$

$<0.001$

47.24

$17.29-129.08$

Score of caregivers in factor 1 of quality of life scale:

Self-realization and pleasure (in terciles)

$\geq 28$

23-27

---
$<0.001$
$<0.001$

1.00

4.17

$1.83-9.50$

$\leq 22$

100.51

$32.17-314.01$

Score of caregivers in factor 2 of quality of life scale:

Control and autonomy (in terciles)

$\geq 13$

$10-12$

0.003

$<0.001$

1.00

3.04

$\leq 9$

8.93

$1.45-6.38$

Total score of caregivers in perceived burden scale (in

terciles)

$\leq 19$

20-27

$---$

1.00

0.22

2.45

$1.14-5.26$

$\geq 28$

$<0.001$

9.27

$4.11-20.90$

Score of caregivers in factor 1 of perceived burden scale:

Role-related stress (in terciles)

$\leq 9$

$10-15$

$--\quad 1.00$

0.445

1.36

$\geq 16$

$<0.001$

4.05

Score of caregivers in factor 2 of perceived burden scale:

Intrapsychic stress (in terciles)

$\leq 1$

$2-3$

$\geq 4$

Score of caregivers in factor 3 of perceived burden scale:

Competences and expectations related to care (in terciles)

$\leq 3$

4-7

$\geq 8$

Number of impaired Basic and Instrumental Activities of

Daily Living in elderly persons receiving care (in terciles)

$0-6$

7-12

13

CDR classification of elderly persons receiving care

$0-0.5$

1-2

3

$---$

0.177

0.001

1.00

1.71

3.34

$0.79-3.72$

$1.62-6.90$
1.00

0.99

2.59

0.008

$---$

0.154

0.214

1.73

1.65

$0.81-3.68$

$0.75-3.62$
$0.45-2.21$

$1.28-5.22$

$* \mathrm{OR}($ Odds Ratio $)=$ Odds ratio for lower life satisfaction; $(\mathrm{n}=45 \mathrm{com} \leq 17, \mathrm{n}=48$ with $18-21$ and $\mathrm{n}=55$ with $\geq 22) ; \mathrm{CI} 95 \%$ OR $=95 \%$ confidence interval for risk ratio; proportional risks models. 
Multivariate logistic regression analysis revealed that the variables that were significantly associated with low life satisfaction scores were self-realization and pleasure (factor 1 of the quality of life scale) and total perceived burden scale score. Thus, caregivers with the greatest risk of poor life satisfaction were those with the lowest score in factor 1 of CASP-
19 (with a chance 6.3 and 101.3 times greater for those who scored in the second tercile and above the third tercile, respectively), and those with the highest overall score on the Zarit scale (risk 3.0 and 5.9 times greater for those who scored in the second tercile and who scored above the third tercile, respectively), as shown in Table 5.

Table 5. Results of multivariate logistic regression analysis for low life satisfaction (n=129). Psychological well-being of elderly caregivers of elderly persons in a family context study. Campinas, São Paulo, Brazil, 2015-2016.

\begin{tabular}{llll}
\hline Selected Variables and Categories & Value- $p$ & O.R.* & CI 95\% O.R.* \\
\hline $\begin{array}{l}\text { Score of caregivers in factor 1 of perceived } \\
\text { quality of life scale (in terciles) }\end{array}$ & & & \\
$\geq 28$ & -- & & \\
$23-27$ & $<0.001$ & 6.00 & -- \\
$\leq 22$ & $<0.001$ & 101.29 & $2.42-16.35$ \\
\hline Total score of caregivers in perceived burden scale (in terciles) & & & \\
$\leq 19$ & --- & 1.00 & --- \\
$20-27$ & $\mathbf{0 . 0 2 2}$ & 357.73 \\
$\geq 28$ & $<\mathbf{0 . 0 0 1}$ & 5.89 & $1.17-7.80$ \\
\hline
\end{tabular}

$*$ OR $($ Odds Ratio $)=$ Odds ratio for lower life satisfaction; $(\mathrm{n}=41 \mathrm{com} \leq 17, \mathrm{n}=41 \mathrm{com} 18-21$ and $\mathrm{n}=47 \mathrm{com} \geq 22) ; \mathrm{CI} 95 \%$ OR $=95 \%$ confidence interval for risk ratio; Stepwise variable selection criteria; proportional risks models.

\section{DISCUSSION}

In terms of age, the present study did not find significant differences in life satisfaction between the 60-64, 65-74 and 75-year-old and older groups. This data resembles that obtained by Tomomitsu et al. ${ }^{10}$. However, there is a paradox between surveys conducted with age groups that also include young and old caregivers. A study conducted by Anderson ${ }^{9}$ using data from the Behavioral Risk Factor Surveillance System found that caregivers between the ages of 18 and 64 were 7.6 times more likely to feel dissatisfied or very dissatisfied with life than caregivers aged over 65 years of age, as younger individuals have other tasks, such as work, in addition to the caring role. On the other hand, Borg and Hallberg ${ }^{12}$ found that life satisfaction indexes decreased with the advancing age of the caregiver. The hypothesis described by the authors is that the elderly have less social resources to assist them in the task of caring, which negatively impacts their perceptions of life satisfaction.

No significant differences between life satisfaction and the gender of caregivers were observed in the present study. Some authors point out that being female and acting as an informal caregiver negatively impacts the satisfaction of male caregivers, as women have other roles in the home besides caring, and generally do not receive support for such tasks? However, literature describes similar findings to those of the present study, such as in the works by Tomomitsu et al. ${ }^{10}$, Hansen and Slagsvold ${ }^{8}$ and Pinquart and Sörensen ${ }^{27}$, who similarly did not find significant differences in the life satisfaction of male and female caregivers, which can be attributed to the difficulties that men face in performing such a role, as they have less experience than women and suffer barriers resulting from male stereotypes. These divergences in data suggest that this theme should be studied in greater depth with larger samples of caregivers of older adults, aiming to compare characteristics such as gender and age and perception of life satisfaction.

The caregivers of the present study who were considered frail, scored low for life satisfaction when compared to those considered robust or pre-frail. In addition to frailty, number of diseases was also negatively associated with the perception of life 
satisfaction of elderly caregivers. Those who reported having three or more diseases were dissatisfied with life, while those who reported having one or two or no diseases, scored high for life satisfaction. Previous research has presented similar data, such as the crosssectional study conducted by Lenardt et al. ${ }^{5}$, which evaluated the health and life satisfaction conditions of 208 caregivers of elderly people with Alzheimer's Disease and found that those who reported having a disease were significantly more dissatisfied with life than those who reported having no diseases. Confirming these results, Tomomitsu et al. ${ }^{6}$, when analyzing 338 caregivers of the elderly, observed that there was a higher frequency of reports of having three or more diseases among those with lower satisfaction. Thus, the association between the health condition of the caregiver and their overall life satisfaction is clear, which can be explained by the set of burdens arising from the task of caring combined with the presence of disease.

The association between the presence of depressive symptoms and low life satisfaction was also evident in the present study. Caregivers with high life satisfaction scores scored lower for depression than dissatisfied life individuals. This finding is consistent with findings in literature, as verified by a study by Moreno et al. ${ }^{13}$ Among the 102 caregivers evaluated, those who scored high for depression scored low for life satisfaction. Hansen and Slagsvold ${ }^{8}$ evaluated 2,553 caregivers of spouses and reported similar data. Caregivers with higher levels of depressive symptoms were more dissatisfied with life. However, this data was applied only to female caregivers, despite the fact that male caregivers also experienced negative emotions and low average life satisfaction.

Among those who scored low for life satisfaction there was a greater tendency to score high in total perceived burden and in the specific factors rolerelated stresses (factor one of the burden scale), intrapsychic tensions (factor two of the burden scale) and competence and expectations related to care (factor three of the burden scale). The results in literature agree with those found in the present study, as Schüz et al. ${ }^{15}$ observed in a study of 346 informal caregivers. Those with higher levels of burden had lower levels of life satisfaction. Chiao et al.$^{28}$ verified similar data in a bibliographic review on the subject.
The studies analyzed found that caregivers with subjective well-being were less burdened than those with low levels of well-being. It should be emphasized that life satisfaction is a protective factor against the perception of burden, and does not mean that the caregiver does not experience negative emotions and events caused by caring ${ }^{16}$.

The association between life satisfaction and quality of life is an important in the present study. Caregivers with low quality of life scores were 100 times more likely to also score low in life satisfaction. In addition, $94.6 \%$ of those with high life satisfaction scores also scored highly in total quality of life score and in the factors self-realization and pleasure (factor 1 of the quality of life scale) and control and autonomy (factor 2 of the quality of life scale). This data is consistent with findings in literature. Dahlrup et al. ${ }^{17}$, Perrin et al. ${ }^{18}$ and Moreno et al..$^{13}$ found that caregivers with high levels of life satisfaction also have high quality of life and, since both are directly associated and influence each other, some authors use measures of life satisfaction as a means of measuring the total quality of life of caregivers ${ }^{29,30}$.

In the present sample of caregivers, the time elapsed since starting to provide care did not significantly influence the perception of poor life satisfaction of the group. Likewise, religious involvement did also not interfere with the life satisfaction of the elderly caregivers of the present study. A possible hypothesis to justify such results would be that religious involvement is quite broad and multidimensional, a factor that may hinder its measurement and association with other factors ${ }^{31}$.

In addition to these variables, the health status of the elderly care recipient did not appear to influence the caregiver's life satisfaction in the present study, since no significant data were found when comparing these factors. This relationship does not corroborate the main findings of gerontological literature, which tends to show that caregivers of individuals who are more dependent in ADL reported feeling more dissatisfied $^{32}$, while those who cared for an elderly person dependent because of cognitive impairments are less satisfied than those who cared for an individual who was dependent due to physical impairments ${ }^{33}$. 
Some limitations of the present study should be considered, such as the non-identification of temporal relationships, as this is a cross-sectional study and is therefore unable to clarify whether the relationship between the variables is casual or not.

\section{CONCLUSION}

In the present study, life satisfaction among caregivers of the elderly seems to be an outcome greatly influenced by their quality of life, their perception of burden and their physical and mental health conditions. The data found are in agreement with most of the findings of gerontological literature on the subject and, although they are not unpublished data, the results are robust and may contribute further to the psychological well-being of these individuals. There are still few studies exclusively dedicated to elderly caregivers and their peculiarities. In this sense, the present study emphasizes the importance of conducting specific research covering this group. Since the reality of elder care becomes increasingly common in the Brazilian and world scenario, it is necessary to develop and apply new strategies of support focusing on this specific and emerging population.

One possible outcome of this research is the investigation of different interventions in the short and medium term, such as support groups, and whether they positively influence the life satisfaction of elderly caregivers, even in the presence of the negative factors verified here, such as frailty and depression. New and more in-depth studies are therefore necessary to produce theoretical support for the planning and development of knowledge about care strategies, as well as for the understanding and improvement of strategies of cognitive-emotional self-regulation aimed at family caregivers of chronically ill and dependent elderly persons.

\section{REFERENCES}

1. Neri AL (org). Palavras-chave em Gerontologia. $4^{\mathrm{a}}$ ed. Campinas, SP: Alínea; 2014. p. 99-105.

2. Campbell A, Converse PE, Rodgers WL. The quality of American life: Perceptions, evaluations, and satisfactions. Russell Sage Foundation Nova Iorque, NY. 1976; 171-208.

3. Thorpe JM, Van Houtven CH, Sleath BL, Clipp, EC. Barriers to Outpatient Care in Community-Dwelling Elderly with Dementia: The Role of Caregiver Life Satisfaction. Journal of Applied Gerontology. 2009; 28(4): 436-460.

4. Mausbach BT, Chattilion EA, Roepke SK, Patterson T, Grant I. A comparison of psychological outcomes in elderly Alzheimer's caregivers and non-caregivers. Am J Geriatric Psychiatry. 2013; 21(1): 5-13.

5. Lenardt MH, Willig MH, Seima MD, Pereira LF. A condição de saúde e satisfação com a vida do cuidador familiar de idoso com Alzheimer. Colombia Médica. 2011; 42 (1): 17-25.

6. Tomomitsu MRSV, Perracini MR, Neri AL. Fatores associados à satisfação com a vida em idosos cuidadores e não cuidadores. Ciência \& Saúde Coletiva. 2014; 19(8): 3429-3440.

7. Hajek A, König HH. Informal caregiving and subjective well-being: evidence of a population-based longitudinal study of older adults in Germany. Jamda, 2016; 17(4): 300-5.

8. Hansen T, Slagsvold B. The psychological effects of providing personal care to a partner: a multidimensional perspective. Health Psychology Research. 2013; 25(1): 126-134.

9. Anderson LA, Edwards VJ, Pearson WS, Talley RC, McGuire LC, Andresen EM. Adult caregivers in the United States: characteristics and differences in wellbeing, by caregiver age and caregiving status. Public Health Research, Practice and Policy. 2013; 10(15): 1-5.

10. Tomomitsu MRSV, Perracini MR, Neri AL. Influência de gênero, idade e renda sobre o bem-estar de idosos cuidadores e não cuidadores. Rev. Brasileira de Geriatria e Gerontologia. 2013; 16(4): 663-68.

11. Figueiredo D, Lima MP, Sousa L. Cuidadores familiares de idosos dependentes com e sem demência: rede social e satisfação com a vida. 2012; 13(1): 117-129.

12. Borg C, Hallberg IR. Life satisfaction among informal caregivers in comparison with non-caregivers. Scandinavian J of Caring Sciences. 2006; 20(4): 427-38. 
13. Moreno JA, Nicholls E, Ojeda N, De Los Reyes-Aragón CJ, Rivera D, Arango-Lasprilla JC. Caregiving in dementia and its impacts on psychological functioning and health-related quality of life: findings from a Colombian Sample. J Cross Cult Gerontol. 2015; 30(4): 393-408.

14. Adelman RD, Tmanova LL, Delgado D, Dions S, Lachs MS. Caregiver Burden: a clinical review. Clinical Review \& Education. 2014; 311(10): 1052-1060.

15. Schüz B, Czerniawski A, Davie N, Miller L, Quinn MG, King C, et al. Leisure time activities and mental health in informal dementia caregivers. Applied Psychology: Health and Well-Being. 2015; 7(2): 230-248.

16. Fianco A, Sartori RD, Negri L, Lorini S, Valle G, Delle Fave A. The relationship between burden and wellbeing among caregivers of Italian people diagnosed with severe neuromotor and cognitive disorders. Res Developmental Disabilities. 2015; 39: 43-54.

17. Dahlrup B, Ekström H, Nordell E, Elmstahl S. Coping as a Caregiver: a question of strain and its consequences on life satisfaction and health-related quality of life. Arch Gerontol Geriatr. 2015; 61: 261-70.

18. Perrin PB, Morgan M, Aretouli E, Sutter M, Snipes DJ, Hoyos GR, et al. Connecting health-related quality of life and mental health in dementia caregivers from Colombia, South America. 2014; 39(3): 499-509.

19. Damasceno A, Delicio AM, Mazo DFC, Zullo JFD, Scherer P, Ng RTY, et al . Validation of the Brazilian version of mini-test CASI-S. Arq Neuro-Psiquiatr. 2005; 63(2b).

20. Diener E, Emmons RA, Larsen RJ, Griffin S. The Satisfaction with Life Scale. J Pers Assess. 1985; 49(1): 71-75.

21. Fried LP, Tangen CM, Walston J, Newman AB, Hirsch $\mathrm{C}$, Gottdiener J et al. Frailty in older adults: evidence of a phenotype. J Gerontol A. 2001; 56(3): 146-56.

22. Almeida OP, Almeida SA. Short versions of the Geriatric Depression Scale: A study of their validity for the diagnosis of major depressive episode according to ICD-10 and DSM-IV. J Geriatr Psychiatry. 1999;14(10): 858-65.
23. Montãno MBMM, Ramos LR. Validade da versão em português da Clinical Dementia Rating. Rev Saúde Pública. 2005; 39(6):912-7.

24. Taunay TCE, Gondim FAA, Macedo DS, MoreiraAlmeida A, Gurgel LA, Andrade LMS et al. Validação da versão brasileira da escala de religiosidade de Duke (DUREL). Rev. Psiquiatric. Clinica. 2012; 39(4): 130.5.

25. Bianchi M, Flesch LD, Alves EVC, Batistoni SST, Neri, AL. Indicadores psicométricos da Zarit Burden Interview aplicada a idosos cuidadores de outros idosos. Rev. Latino Americana de Enfermagem. 2016; 24(2835).

26. Hyde M, Wiggins RD, Blane DB. A measure of quality of life in early old age: the theory, development and properties of a needs satisfaction model (CASP-19). Aging Mental Health. 2003; 7(3): 186-94.

27. Pinquart M, Sörensen S. Gender diferences in caregiver stressors, social resources, and health: a meta-analysis. J Gerontol B. 2006; 61(1): 33-45.

28. Chiao CY, Wu HS, Hsiao CY. Caregiver burden for informal caregivers of patients with dementia: A systematic review. International Nursing Review. 2015; 62: 340-350.

29. Nogueira CA, Alves FP, Coura AS, Vieira CNK, Enders BC, França ISX. Percepção da qualidade de vida dos cuidadores de octogenários. Rev Rede Enfermagem Nordeste. 2013; 14(1): 32-41.

30. Lim J, Zebrack B. Caring for family members with chronic physical illness: a critical review of caregiver literature. Health and Quality of Life Outcomes. 2004; 2: 50-59.

31. Hebert RS, Weinstein E, Martire LM, Schulz R. Religion, spirituality and the well-being of informal caregivers: a review, critique, and research prospectus. Aging \& Mental Health. 2006; 10(5): 497-520.

32. Goldsworthy B, Knowles S. Caregiving for Parkinson's Disease Patients: An Exploration of a Stress-Appraisal Model for Quality of Life and Burden. J Gerontol B. 2008; 63 (6): 372-376

33. Sequeira C. Difficulties, coping strategies, satisfaction and burden in informal Portuguese caregivers. Journal of Clinical Nursing. 2013; 22(3): 491-500. 